\title{
A Comparative Study on the Postoperative Analgesic Effects of the Intraperitoneal Instillation of Bupivacaine Versus Normal Saline Following Laparoscopic Cholecystectomy
}

\author{
Shashikanth Vijayaraghavalu ${ }^{1}$, Ezhil Bharthi Sekar ${ }^{2}$ \\ 1. General Surgery, ACS Medical College Hospital, Chennai, IND 2. Anaesthesiology, ACS Medical College Hospital, \\ Chennai, IND
}

Corresponding author: Ezhil Bharthi Sekar, ezhilbharthi90@gmail.com

\section{Abstract \\ Background}

Laparoscopic cholecystectomy is widely performed, and postoperative pain is an important factor in patient morbidity during recovery. Various modalities for postoperative pain relief have been proposed, with varying levels of success such as intravenous or intramuscular non-steroidal anti-inflammatory drugs (NSAIDs) and opioids, infiltration at the incision site with local anesthetics, intraperitoneal infiltration of local anesthetics, intraperitoneal infiltration of local anesthetics with adjuvants, regional anesthesia techniques such as epidurals and nerve blocks. The study was aimed to evaluate the efficacy of intraperitoneal instillation of bupivacaine and normal saline on postoperative analgesia, postoperative nausea, and vomiting after laparoscopic cholecystectomy.

\section{Methods}

This prospective, controlled, and randomized study included 60 American Society of Anesthesiologists (ASA) I and ASA II patients, aged 18-50 years, who were scheduled for laparoscopic cholecystectomy under general anesthesia. The patients were classified randomly into two groups with an equal number of participants: Group B received intraperitoneal instillation of $30 \mathrm{ml}$ of plain bupivacaine $0.5 \%$ and Group N received $30 \mathrm{ml}$ of normal saline. Postoperative pain was recorded using the visual analog scale (VAS) for 24 hours after surgery. Postoperative shoulder pain, nausea, vomiting, and the time taken to request rescue analgesia were noted.

\section{Results}

Patients receiving intraperitoneal bupivacaine showed a significant reduction in postoperative pain for the first six hours postoperatively $(\mathrm{P}=0.04)$; moreover, the time taken to request rescue analgesia requirement was prolonged $(\mathrm{P}=0.04)$. Side effects, such as nausea and vomiting, were similar between the two groups ( $\mathrm{P}$

Review began 03/20/2021 Review ended 03/25/2021 Published 03/27/2021

\section{(c) Copyright 2021}

Vijayaraghavalu et al. This is an open access article distributed under the terms of the Creative Commons Attribution License CC-BY 4.0., which permits unrestricted use, distribution, and reproduction in any medium, provided the original author and source are credited.
$=0.1$ and $\mathrm{p}=0.09$, respectively) while shoulder pain was significantly lower in the bupivacaine group $(\mathrm{P}=$ $0.04)$.

\section{Conclusion}

Bupivacaine is effective in reducing postoperative pain, and it prolongs the requirement time for rescue analgesia. It also reduces the incidence of shoulder pain but does not decrease postoperative nausea and vomiting.

Categories: Anesthesiology, General Surgery

Keywords: bupivacaine, laparoscopy, cholecystectomy, analgesia, intraperitoneal, postoperative pain, shoulder pain, nausea, vomiting, local anesthetics

\section{Introduction}

Laparoscopic cholecystectomy is widely performed, and it has replaced open cholecystectomy as the gold standard for cholelithiasis. Laparoscopic surgeries are favored over open surgeries because they have a number of advantages such as reduced postoperative pain and analgesic requirement, improved postoperative respiratory function, rapid return of gastrointestinal function, a reduced stress response to surgery and recovery time, less postoperative wound infection, and improved cosmetic appearance [1-3].

Postoperative pain is an important factor contributing to patient morbidity during recovery. After laparoscopic cholecystectomy, pain can arise from the incision site (somatic pain), visceral structures (visceral pain) [4], and shoulder tip (referred pain from the subdiaphragmatic region). Visceral pain occurs due to the stretching of the parietal peritoneum, the release of inflammatory mediators of pain, and the 
irritation produced by blood. Referred shoulder pain is often mild and is due to the irritation of the diaphragm by residual gas [5].

Various modalities are used for postoperative pain relief, including intravenous or intramuscular NSAIDs [6] and opioids [7], infiltration at the incision site with local anesthetics [8], intraperitoneal infiltration of local anesthetics [8], local anesthetics with adjuvants [9], and regional anesthesia techniques such as epidurals and nerve blocks [10-11]. These have been found to have variable rates of success.

The present study was conducted to evaluate the effects of the intraperitoneal instillation of bupivacaine and normal saline on postoperative analgesia and postoperative nausea and vomiting (PONV) in patients undergoing laparoscopic cholecystectomy.

\section{Materials And Methods}

This randomized, prospective, double-blind study was conducted in ACS Medical College Hospital from June 2020 to December 2020, after obtaining approval from the Institutional Ethics Committee, and written informed consent was obtained before surgery from all the patients participating in the study.

The study population consisted of 60 male and female patients, ranging in age from 18 to 50 years, with either an American Society of Anesthesiologists (ASA) I or ASA II physical classification status that was scheduled for elective laparoscopic cholecystectomy under general anesthesia. Exclusion criteria were patient refusal, pregnant or lactating patients, a body mass index (BMI) of $>40$, allergy to local anesthetics, patients with cardiac, pulmonary, neurological, and renal diseases, any patient who needed conversion to open cholecystectomy, previous history of abdominal surgeries, and duration of surgery of > two hours.

The patients were randomized into two groups of 30 patients each using sequentially numbered envelopes. To maintain the double-blind nature of the study, the randomization and preparation of the drug for injection were done by an anesthesiologist not involved in the study. Group $\mathrm{N}$ received $30 \mathrm{ml}$ of normal saline and Group B received $30 \mathrm{ml}$ of $0.5 \%$ plain bupivacaine. The postoperative follow-up of the study participants was done by the co-author who was blind to the patient group assignment.

All the patients fasted overnight, and the preoperatively enrolled patients received instructions about the visual rating scale employed in this study to indicate their pain. On arrival to the operating room, an 18gauge intravenous (IV) cannula was secured and IV fluids at $2 \mathrm{ml} / \mathrm{kg}$ were started. The Association of Anaesthetists of Great Britain and Ireland (AAGBI) standards for monitoring started and baseline vital parameters were noted.

General anesthesia with endotracheal intubation was administered in all patients using propofol $2 \mathrm{mg} / \mathrm{kg}$, fentanyl $2 \mathrm{ug} / \mathrm{kg}$, and vecuronium $0.1 \mathrm{mg} / \mathrm{kg}$ after pre-oxygenation with $100 \%$ oxygen for three minutes. The airway was secured with an appropriately sized, cuffed endotracheal tube. Anesthesia was maintained with $50 \%$ oxygen and $50 \%$ air with $1 \%$ isoflurane and intermittent doses of muscle relaxant. Minute ventilation was adjusted to maintain End-tidal $\mathrm{CO}_{2}$ (EtCO2) between 35 and $40 \mathrm{mmHg}$. No other intraoperative analgesic supplementation was used. $\mathrm{CO}_{2}$ was used to institute pneumoperitoneum, and the intraabdominal pressure was maintained between 12 and $14 \mathrm{mmHg}$. The patients were placed in a 15-30-degree reverse Trendelenburg position with a left lateral tilt.

At the end of the surgery, the study drugs, as per group allocation, were instilled in equal amounts into the sub-diaphragmatic space and intraperitoneally under direct vision, and the patients were placed in the Trendelenburg position. The pneumoperitoneum was removed carefully by manual compression and suction of the abdomen at the end of the procedure through the trocar. The patients were reversed with intravenous neostigmine and glycopyrrolate and extubated. All patients were transferred to the post-anesthesia care unit following extubation.

The intensity of postoperative pain was recorded for all patients using the visual analog scale (VAS) score at $0,2,4,6,12$, and 24 hours, with 0 referring to the time the patient was transferred to recovery. In patients that complained of moderate to severe pain, $100 \mathrm{mg}$ of tramadol was administered IV as a rescue analgesia treatment, and the time interval to the first request for rescue analgesia was noted. Adverse effects of nausea, vomiting, and shoulder pain over the course of 24 hours were noted. All postoperative findings were compared between the two study groups.

Data were collected, tabulated, and coded, and then analyzed using repeated-measures analysis of variance (ANOVA), the student's t-test, and the paired t-test. The Statistical Package of the Social Sciences (SPSS) version 15 for Windows (SPSS Inc., Chicago, IL) was employed for the data analysis. A difference with a $p$ level of $<0.05$ was considered statistically significant.

\section{Results}

All the patients in Group B and Group N were comparable in terms of age, weight, sex, and the duration of 


\section{Cureus}

surgery (Table 1).

\begin{tabular}{|c|c|c|c|c|}
\hline & Age & Weight & Sex & Duration of Surgery \\
\hline Group N (mean) & 40.13 & 77.83 & M (19) F (11) & $62.16 \pm 15.18$ \\
\hline Group B (mean) & 39.8 & 76.73 & M (19) F (11) & $64.66 \pm 15.64$ \\
\hline P-value & 0.85 & 0.67 & & 0.09 \\
\hline
\end{tabular}

TABLE 1: Demographic characteristic of the patients in the two study groups

The VAS score was assessed at zero hours (the time when the patient was transferred to recovery) and at two, four, six, 12, and 24 hours. The mean VAS score in Group B was 1.56 at zero hours, 1.99 at two hours, 2.11 at four hours, 2.45 at six hours, 3.36 at 12 hours, and 3.53 at 24 hours. The mean VAS score in Group N was 3.46 at zero hours, 3.83 at two hours, 3.90 at four hours, 4.22 at six hours, 4.32 at 12 hours, and 4.38 at 24 hours. The VAS score was statistically significantly lower in Group B at zero, two, four, and six hours in comparison to Group N; the P-value was 0.05 ( 0 hours), 0.04 ( 2 hours), 0.04 ( 4 hours), and 0.04 (6 hours). The VAS score between the two groups did not show any significant difference at 12 hours $(P=0.1)$ and 24 hours $(P=0.7)$ (Table 2).

\begin{tabular}{|c|c|c|c|c|c|c|c|}
\hline & $\begin{array}{l}\text { VAS score } 0 \\
\text { hours }\end{array}$ & $\begin{array}{l}\text { VAS score } 2 \\
\text { hours }\end{array}$ & $\begin{array}{l}\text { VAS score } 4 \\
\text { hours }\end{array}$ & $\begin{array}{l}\text { VAS score } 6 \\
\text { hours }\end{array}$ & $\begin{array}{l}\text { VAS score } 12 \\
\text { hours }\end{array}$ & $\begin{array}{l}\text { VAS score } 24 \\
\text { hours }\end{array}$ & $\begin{array}{l}\text { Time taken to request rescue } \\
\text { analgesia }\end{array}$ \\
\hline $\begin{array}{l}\text { Group N } \\
\text { (mean) }\end{array}$ & $3.46 \pm 1.27$ & $3.83 \pm 1.39$ & $3.90 \pm 1.21$ & $4.22 \pm 1.26$ & $4.32 \pm 1.14$ & $4.38 \pm 1.17$ & $70.44 \pm 24.73$ \\
\hline $\begin{array}{l}\text { Group B } \\
\text { (mean) }\end{array}$ & $1.56 \pm 0.89$ & $1.99 \pm 0.92$ & $2.11 \pm 0.95$ & $2.45 \pm 1.11$ & $3.36 \pm 1.18$ & $3.53 \pm 1.04$ & $182.83 \pm 24.05$ \\
\hline$P$ value & 0.05 & 0.04 & 0.04 & 0.04 & 0.1 & 0.7 & 0.04 \\
\hline
\end{tabular}

TABLE 2: Postoperative visual analog scale score and analgesia requirements

The mean time taken for the first requirement for rescue analgesia was 182.83 minutes in Group B and 70.44 minutes in Group N, which was statistically significant $(\mathrm{P}=0.04)$ (Table 2).

In Group N, postoperative nausea occurred in two patients and vomiting occurred in three patients. In Group $\mathrm{B}$, nausea occurred in one patient and vomiting occurred in two patients. The incidence of PONV was not statistically significant between the groups $(\mathrm{P}=0.1$ and $\mathrm{p}=0.09$, respectively). Shoulder pain was seen in 17 patients in Group N and seven patients in Group B, which was statistically significant ( $\mathrm{P}=0.04)$ (Table 3).

\begin{tabular}{|c|c|c|c|}
\hline & Group N (n=30) (\%) & Group B (n=30) (\%) & P-value \\
\hline Nausea & $2(6 \%)$ & $1(3 \%)$ & 0.1 \\
\hline Vomiting & $3(10 \%)$ & $2(6 \%)$ & 0.09 \\
\hline Shoulder Pain & $17(56 \%)$ & $7(23 \%)$ & 0.04 \\
\hline
\end{tabular}

TABLE 3: Postoperative side effects

\section{Discussion}

Laparoscopic cholecystectomy is a widely performed, common, elective procedure. Postoperative pain is comparatively less after laparoscopic cholecystectomy than after an open cholecystectomy, but it still remains a significant cause for morbidity [12]. Patient education regarding the degree of pain they may encounter, an explanation of the pain assessment tools being used and the modalities of pain treatment available, and reassurance regarding the pain they may experience can help reduce the patients' anxiety and 
postoperative pain incidence.

Patients undergoing laparoscopic cholecystectomy suffer considerable pain on the day of surgery, frequently requiring opioid analgesia. After laparoscopic cholecystectomy, several types of pain can arise. Parietal pain is due to the placement of trocars through the abdominal wall. It is superficial and can be located by the patient. Visceral pain is due to intraperitoneal dissection and insufflation of $\mathrm{CO}_{2}$, resulting in distension of the abdominal wall. This type of pain is dull, more diffuse than parietal pain, and difficult to locate. The prolonged elevation of the diaphragm and residual gas from pneumoperitoneum leads to referred shoulder tip pain. Normal saline infiltration reduces visceral pain and referred pain by causing dilution of the inflammatory markers, replacing the gas above the liver, and reducing the space between the liver and the diaphragm [13]. Bupivacaine is the most common local anesthetic used intraperitoneally for postoperative pain relief because of its high potency and longer duration of action.

The demographic data were similar in both study groups. The overall duration of surgery was similar for both groups. In our study, the VAS score was lower in Group B (receiving intraperitoneal instillation of bupivacaine) in comparison to Group N (receiving normal saline). This finding was similar to the results reported in Devalkar and Salgaonkar [14] and Suma and Vikranth [15]. Raetzell et al. compared lower concentrations of bupivacaine $(0.125 \%$ and $0.25 \%)$ with normal saline and found no difference in the pain scores between the groups [16]; this could be attributed to the lower concentration of bupivacaine that was used. In the meta-analysis by Choi et al., which studied 39 random control trial reviews, the authors concluded that intraperitoneal local anesthetics did not significantly reduce parietal pain and exhibited a favorable analgesic effect towards visceral pain and shoulder pain [17].

There are a few studies in which the administration of a local anesthetic did not show any efficacy. These failures could be due to the use of a lower drug dose, a lower concentration, or because the entire dose was infiltrated under the right hemidiaphragm [16,18-19].

In our study, postoperative shoulder tip pain was lower in Group B than Group N. Putta et al. also showed that the incidence of shoulder pain was significantly reduced in groups receiving bupivacaine in comparison to those receiving normal saline and that the timing of the bupivacaine infiltration (pre-emptive or postsurgical) was not significant [20].

In our study, the mean time taken for the first dose of analgesic was 182 minutes in Group B and 70 minutes in Group N. Similarly, the study by Sulekha showed that the dosing of rescue analgesia was more frequent and the highest in patients that received normal saline in comparison to those that received bupivacaine [21]. A study on laparoscopic pelvic surgery conducted by Shalan et al. found that the pain score and required analgesic dose were lower in the bupivacaine group [22].

No statistically significant difference was found in the incidence of PONV in Group B (one and two patients, respectively) and Group N (two and three patients, respectively). No side effects or toxicity were recorded due to bupivacaine use. Hazinedarogle et al. reported the same results [23]. Goldstein A et al. showed a lower rate of PONV in patients that were administered bupivacaine [24].

\section{Conclusions}

In our study, we found that bupivacaine reduces postoperative pain and prolongs the requirement time of rescue analgesia. It also reduces the incidence of shoulder pain after laparoscopy. We conclude that the intraperitoneal and subdiaphragmatic instillation of $0.5 \%$ bupivacaine is a safe and effective method for providing postoperative analgesia without significant side effects.

\section{Additional Information \\ Disclosures}

Human subjects: Consent was obtained or waived by all participants in this study. ACS Medical College Hospital Institutional Ethics Committee issued approval NA. Animal subjects: All authors have confirmed that this study did not involve animal subjects or tissue. Conflicts of interest: In compliance with the ICMJE uniform disclosure form, all authors declare the following: Payment/services info: All authors have declared that no financial support was received from any organization for the submitted work. Financial relationships: All authors have declared that they have no financial relationships at present or within the previous three years with any organizations that might have an interest in the submitted work. Other relationships: All authors have declared that there are no other relationships or activities that could appear to have influenced the submitted work.

\section{References}

1. Talpur KAAH, Malik AM, Memon IQ, Laghari AA, Qureshi JN, Sangrasi AK: Factors responsible for prolonged postoperative hospital stay after laparoscopic cholecystectomy. Pak J Med Sci. 2011, 27:759-762.

2. Jensen K, Kehlet H, Lund CM: Post-operative recovery profile after laparoscopic cholecystectomy: a 
prospective, observational study of a multimodal anaesthetic regime. Acta Anaesthesiol Scand. 2007, 51:464-71. 10.1111/j.1399-6576.2006.01251.x

3. Morsy KM, Abdalla EEM: Postoperative pain relief after laparoscopic cholecystectomy: intraperitoneal lidocaine versus nalbuphine. Ain Shams J Anesthesiol. 2014, 7:40-44.

4. Bisgaard T, Warltier DC: Analgesic treatment after laparoscopic cholecystectomy: a critical assessment of the evidence. Anesthesiology. 2006, 104:835-46. 10.1097/00000542-200604000-00030

5. Singla S, Mittal G, Raghav, Mittal RK: Pain management after laparoscopic cholecystectomy-a randomized prospective trial of low pressure and standard pressure pneumoperitoneum. J Clin Diagn Res. 2014, 8:92-4. 10.7860/JCDR/2014/7782.4017

6. Gupta A, Bah M: NSAIDs in the treatment of postoperative pain . Curr Pain Headache Rep. 2016, 20:62. 10.1007/s11916-016-0591-7

7. Scott AD, Greville AC, McMillan L, Wellwood JM: Laparoscopic laser cholecystectomy: results of the technique in 210 patients. Ann R Coll Surg Engl. 1992, 74:237-241.

8. Yeh CN, Tsai CY, Cheng CT, et al.: Pain relief from combined wound and intraperitoneal local anesthesia for patients who undergo laparoscopic cholecystectomy. BMC Surg. 2014, 14:28. 10.1186/1471-2482-14-28

9. Shukla U, Prabhakar T, Malhotra K, Srivastava D, Malhotra K: Intraperitoneal bupivacaine alone or with dexmedetomidine or tramadol for post-operative analgesia following laparoscopic cholecystectomy: a comparative evaluation. Indian J Anaesth. 2015, 59:234-9. 10.4103/0019-5049.155001

10. O'Donovan B, Martin B: The novel use of an external oblique nerve catheter after open cholecystectomy . Cureus. 2021, 13:e13580. 10.7759/cureus.13580

11. Li J, Li L, Zhang X, et al.: Paravertebral block with compound betamethasone in laparoscopic cholecystectomy: a double-blind randomized controlled trial. Cureus. 2019, 11:e6023. 10.7759/cureus.6023

12. Gan TJ: Poorly controlled postoperative pain: prevalence, consequences, and prevention . J Pain Res. 2017, 10:2287-2298. 10.2147/JPR.S144066

13. Tsimoyiannis EC, Siakas P, Tassis A, Lekkas ET, Tzourou H, Kambili M: Intraperitoneal normal saline infusion for postoperative pain after laparoscopic cholecystectomy. World J Surg. 1998, 22:824-8. $10.1007 /$ s002689900477

14. Devalkar PS, Salgaonkar SV: Intraperitoneal instillation of $0.25 \%$ bupivacaine for laparoscopic cholecystectomy: Effect on postoperative pain. IJCMAAS. 2016, 12:91-5.

15. Suma S, Vikranth SN: Intra-peritoneal bupivacaine instillation for post-operative pain relief after laparoscopic cholecystectomy: a prospective study. Int J Contem Surg. 2019, 7:108-114.

16. Raetzell M, Maier C, Schröder D, Wulf H: Intraperitoneal application of bupivacaine during laparoscopic cholecystectomy - risk or benefit?. Anesth Analg. 1995, 81:967-972.

17. Choi GJ, Kang H, Baek CW, Jung YH, Kim DR: Effect of intraperitoneal local anesthetic on pain characteristics after laparoscopic cholecystectomy. World J Gastroenterol. 2015, 21:13386-95. 10.3748/wjg.v21.i47.13386

18. Chundigar T, Hedges AR, Morris R, Stamatakis JD: Intraperitoneal bupivacaine for effective pain relief after laparoscopic cholecystectomy. Ann R Coll Surg Engl. 1993, 75:437-439.

19. Scheinin B, Kellokumpu I, Lindgren L, Haglund C, Rosenberg PH: Effect of intraperitoneal bupivacaine on pain after laparoscopic cholecystectomy. Acta Anaesthesiol Scand. 1995, 39:195-8. 10.1111/j.13996576.1995.tb04042.x

20. Putta PG, Pasupuleti H, Samantaray A, Natham H, Rao MH: A comparative evaluation of pre-emptive versus post-surgery intraperitoneal local anaesthetic instillation for postoperative pain relief after laparoscopic cholecystectomy: a prospective, randomised, double blind and placebo controlled study. Indian J Anaesth. 2019, 63:205-211. 10.4103/ija.IJA_767_18

21. Singh D, Bogra J, Saxena S, Chaudhary A, Bhusan S, Chandra G: The effect of intraperitoneal bupivacaine for post-operative pain management in patients undergoing laparoscopic cholecystectomy: a prospective double-blind randomized control study. Open J Anesthesiol. 2013, 4:64-69. 10.4236/ojanes.2013.33045

22. Shalan H, Badaway A, Yousef H, Nazar M: Effect of intraperitoneal bupivacaine on post-operative pain following laparoscopic pelvic surgery. Gynecol Endosc. 2002, 11:371-375. 10.1111/j.1365-2508.2002.00557.x

23. Hazinedaroglu SM, Kayaoglu HA, Ates Y, Ertürk S, Butuner C, Turkcapar AG: Intraperitoneal bupivacaine for postoperative pain relief after laparoscopic cholecystectomy. Pain Med. 2006, 7:539-41. 10.1111/j.15264637.2006.00241.x

24. Goldstein A, Grimault P, Henique A, Keller M, Fortin A, Darai E: Preventing postoperative pain by local anesthetic instillation after laparoscopic gynecologic surgery: a placebo-controlled comparison of bupivacaine and ropivacaine. Anesth Analg. 2000, 91:403-7. 10.1097/00000539-200008000-00032 